\title{
The effect of transparency on a three-cycle model of manipulative discourse
}

\begin{abstract}
It is assumed that manipulative discourse can carry various types of messages on the continuum of sincerity, such as: truth, persuasion (argumentation), deception and manipulation. These different intended meanings can cause variations within the 'transparency factor'. The transparency factor is controlled by specific social and pragmatic factors. Generally speaking, manipulative discourse is far away from transparency because it entails the use of implicit strategies and processes to achieve a final goal. The highly transparent type of discourse is the testimony where the speaker's intention is to present truth that is supported by explicit strategies and processes. Within this continuum, there is the persuasion where the speaker's intention is to convince the addressee without exerting any power upon the receiver. Other types, such as coercion and deception, may show a lower degree of transparency because they are used to mislead the hearer with or without the use of the social effect such as 'power'. Accordingly, a theoretical framework which treats manipulation as a three-cycle of the meaning-making process is proposed. It is assumed that this model helps in classifying manipulative texts into different types based on the transparency factors. The aim of this study is to provide a theoretical framework that can be adopted by researchers to analyze types of discourse in terms of transparency taking into consideration the speaker, the text itself and the hearer. All these factors in the three-cycle model help in shaping the degree of transparency that a text may show.
\end{abstract}

Keywords: manipulation, transparency, deception, testimony.

\section{Introduction}

A manipulative piece of discourse is developed through stages. According to Fairclough (2003), a text is produced based on the 'meaning-making' process which makes use of both explicit and implicit factors. Fairclough divides the process of meaning-making into different stages starting from the production of discourse, the discourse itself and ending with the reception of discourse. The production stage focuses on the producer (Speaker).The second stage involves the development of the Text itself, and the third stage is the reception of the texts that has a close relation with the receiver who is the (Hearer).

The aim of this study is to build a connection between these stages and the transparency factor. The variations in the degree of transparency are found between the first and the last stages where the interplay of roles among the deceiver and the receiver is evident. In other words, the degree of transparency is highly dependent on both speaker's and hearer's intention. When the speak- 
er is simply lying, he creates a low degree of transparency which stands in contract with giving truth. Similarly, the hearer may perceive the speech as a complete truth which has a high degree of transparency or as a lie which has a low degree of transparency. The perception is evaluated regardless of the speaker's intention. The second stage focuses on the real text itself that displays a message with various degrees of transparency as well. The testimony discourse, for example, is highly transparent in contrast with the manipulative discourse which is the least transparent. Other types of discourse may appear in between such as persuasion, coercion and deception. They are characterized by a degree of transparency that may differ from the ones that can be found in testimony and manipulative discourses. A set of factors help in shaping the degree of transparency that these texts may reflect.

The aim of this study is to propose a theoretical framework which focuses on the classification of discourse in terms of transparency by emphasizing the speaker's intention and strategies, the texts features and the hearer's attitude.

\section{Towards the theoretical framework}

The analytical framework adopted here relies heavily on Blass's (2005) and de Saussure's (2005) realizations of the manipulation theory. Within this treatment, the main acts of manipulation are mainly related to the truth conditions of the intentional statements. The statements, therefore, are treated as propositions that can be true or false based on proof or reasons. The manipulation theory is an intentional act that has specific goals whether these goals represent a mere fact or a mere lie with or without proof. Accordingly, the manipulative discourse is "a discourse produced in order to persuade the addressee of a set of propositions P1... Pn of type T with appropriate strategies S" (de Saussure 2005: 120).

This paper is based on the assumption that manipulative discourse has to go through a threecycle process which includes the speaker, the text itself and the hearer. This assumption is supported by Fairclough (2003), who states that there are stages in developing discourse starting from the production and ending with perception. The first participant is the speaker or the communicator $(\mathrm{S})$ who has a specific goal $(\mathrm{G})$. This goal can be manifested through propositions which can be true or truth-conditionally $(\mathrm{T})$ or false or truth-functionally defective (F).The speaker needs a variety of strategies (ST) to achieve his final goal. When the proposition is (T), the manipulation discourse under goes the 'testimony type'. Testimony is a kind of text that deals with facts whose truth value is effectively evident with a desirable effect for both the speaker and the hearer. Testimony has a beneficial outcome to both of them (Blass 2005). However, if the proposition is false, it falls within the general headings of 'coercion', 'deception' and 'manipulation'. The relevance of the truth or false value is not relevant when proof is needed. This comes under the title argumentation (A) or persuasion (P) (Blass 2005). According to Blass, manipulation can be manifested in three forms, namely, testimony, deception and argumentation or persuasion. These three forms are different forms of communication that are used to influence people and make them "believe and do what one wants them to do" (Blass 2005: 171). 
The present study proposes five types of equations which represent in short the previously stated types of manipulative texts:

a. Testimony $(\mathrm{T})$ is a proposition $(\mathrm{P})$ about $(\mathrm{F})$ facts. $(\mathrm{T}+\mathrm{P}=\mathrm{F})$

b. Deception $(\mathrm{D})$ is a proposition about $(\mathrm{L})$ lies. $(\mathrm{D}+\mathrm{P}=\mathrm{L})$

c. Argumentation (A)/persuasion is a proposition about (F) facts or (L) lies with reasons. $(\mathrm{A}+\mathrm{P}=\mathrm{F}$ or $\mathrm{L} / \mathrm{R})$

d. Coercion $(\mathrm{C})$ is a proposition about $(\mathrm{L})$ lies with $(\mathrm{PW})$ power.

e. Manipulation $(\mathrm{M})$ is a proposition of $(\mathrm{L})$ lies with cognitive effect.(CE)

The second participant is the hearer $(\mathrm{H})$ or the receiver of the proposition who acts according to his set of beliefs or the so-called cognitive environment (CE) (de Saussure 2005).The cognitive

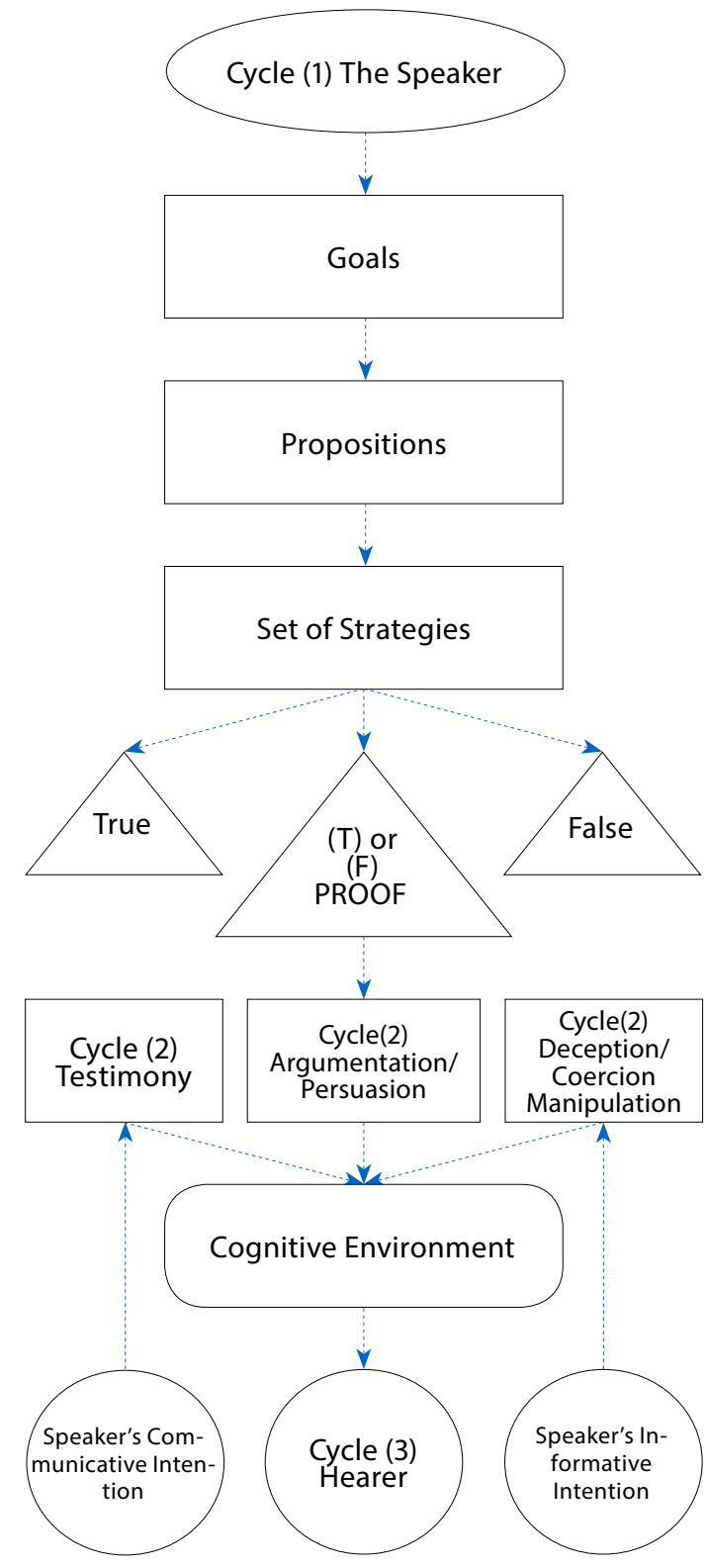
environment carries its own truth value regardless of whether the proposition is true or false. The propositions need to go through two types of intentions, that is, the communicative 'CI' and the informative 'II' to be processed by the hearer. These two intentions fall within the 'Relevance Theory'. It indicates that the speaker's intentions must be acknowledged by the hearer in order to start the interpretive process. The first one triggers "expectations of relevance" which implies that the hearer knows that there is a message from the speaker and the second is pragmatically enriched by the use of different strategies and it creates "relevant consequences". This implies that the hearer needs to improve his knowledge of reality. In other words, the hearer suspects the speaker's propositions and that the speaker has hidden intentions (ibid:134). The figure below shows the three main cycles in the process of building a manipulative piece of discourse.

Figure 1. The suggested model of the three-cycle process of building manipulative discourse 


\section{Cycle one: The speaker}

The role of the participants in manipulative discourse can be accounted for semantically and pragmatically. Based on the proposed Ilia's (2005) conception, the semantic approach to the role of the participants can be exemplified in terms of three core roles which are Agent, Co-Agent and Patient. These roles are associated with a particular discourse and they control the type of relationship the speaker may have with other participants.

Agent generally acts on the patient in specific settings. However, it is not always the case as there are situations in which the roles can be unidirectional. It is exemplified in a specific speech act exchange between the interviewee and the interviewer especially when the interviewee has prior social status as a president. The two roles, namely the agent and the patient, can be applied in such a case. The patient's role is clearly evident as he has to answer the questions which are directed by the agent or the interviewer. Similarly, the agent role is evident when he performs the speech acts as he responds to or comments on the questions (Ilie 2005).The co-agent appears in a situation in which the agent cannot fulfill his own goal, thus, the co-agent has to carry on a joint action to pursue the agent goal. In such a case, two possibilities are evident. The first one is when both agents have the same goal and the second possibility is when the two agents have different goals, that is, the two inter-agents should rely on each other to achieve their goals. This is called the cooperation in communication (Rigotti 2005).

From the view point of transparency, it can be assumed in this study that the speakers are semantically the agents in all these types of manipulative texts. They perfectly employ the actions but they differ in the way they implement their strategies. In testimony, the agent is quite sure of the truthfulness of his message and he/she tends to be as clear as possible. The degree of the transparency of the agent is highly dependent upon his intention. Thus, the higher degree of transparency will be evident when he personalizes himself as an active agent only without affecting others or minimizing the opponents. The lower degree of transparency is evident when the speaker has the two contrastive intentions of maximizing his role as an active agent and minimizing the opponents as a passive agent.

In this respect Vadia (2016) states that the speaker personalizes himself as an active, competent character whereas the opponent is given the submissive position. The following figure shows the degree of trans- Figure 2. The transparency of the speaker parency from the semantic perspective. from the semantic perspective 
Pragmatically speaking, speech acts have a close relation with the participant roles as they tend to contextualize the participants roles. In this respect Ilie (2005: 197) states that: "At the utterance level, the roles of Speaker and Hearer can be constructed as interaction macro-roles acting as pragmatic counterparts of the semantic role of Agent and Co-Agent”. According to Ilie (2005), the directive and commissive speech acts assign different roles to the speaker and the hearer. In commissive acts the speaker is the agent whereas in directive the hearer is urged to do something. Therefore, the speaker has a leading position which gives him or her enough power. Commissive acts commit the speaker to perform an action whereas the directives are primarily targeted to a group of people or the patient to comply with the agents' actions. Similarly, Vadai (2016) states that the speaker can make use of different types of speech acts based on his intention. These speech acts include a set of expressives, representatives and commissives. The speaker's intended use of these speech acts has a close relation with the truth value of the intended message. Generally, a speaker uses assertion acts to carry truth claims, but it may be used differently by a manipulator who intends to behave as the knower of the information and the seer of the future.

It is proposed here that the difference in usage creates different degrees of transparency, that is, whenever the speaker uses assertion acts such as expressive, representative and commissive in a direct way, he is building a testimony type of discourse. Similarly, in persuasion discourse the speaker can make use of different speech acts to convince the hearer. The persuasion in this case seems to have a mid degree of transparency because it is highly connected with the hearer's belief or disbelief. The logical reasoning is a key factor in convincing the hearer. On the other hand, when the speaker uses these acts to promote inequality and discursive ideologies, he is building less transparent discourse. In this respect Vadia (2016) states that the manipulator may use expressives in terms of polarization to emphasize the positive self-presentation and negative presentation of others or opponents, depending on lying, blurring and defocusing.

The final assumption that has to be raised is that commissives are used to represent vague promises and threats where the truth value of these promises and threats are questionable. The same is applicable to coercion texts. Directives that have the forms of begs and request are used to indicate power-dependence. Similarly, declaratives in form of announcements may occur because they indicate power. The representatives with truth claims and expressives with positive self and negative others are also used. This type implies a mid degree of transparency because the speaker has a kind of power that he can impose through the use of both declaratives (the announcement) and the representative with a truth claim. The mid transparency is also evident because the speaker may use half-truth based on his power. Portis et al. (2000) state the half-truth is a strategy used to persuade people. It is implemented by being cognizant rather than being consistent or having a 'characterological' sense.

Manipulative discourse appears as the last option on the continuum of sincerity with the least degree of transparency because speakers tend to violate most of the pragmatically based rules. In this respect, Maillat \& Oswald (2009) state that in a manipulative text, speakers tend to violate the felicity condition particularly the sincerity condition. In manipulative discourse, the speaker makes use 
of two important aspects where he maximizes himself and minimizes the others. Therefore he may use expressive polarization, representative dissimulation and vague promises or threats. The figure below shows the degrees of transparency from pragmatic perspectives in manipulative discourse.

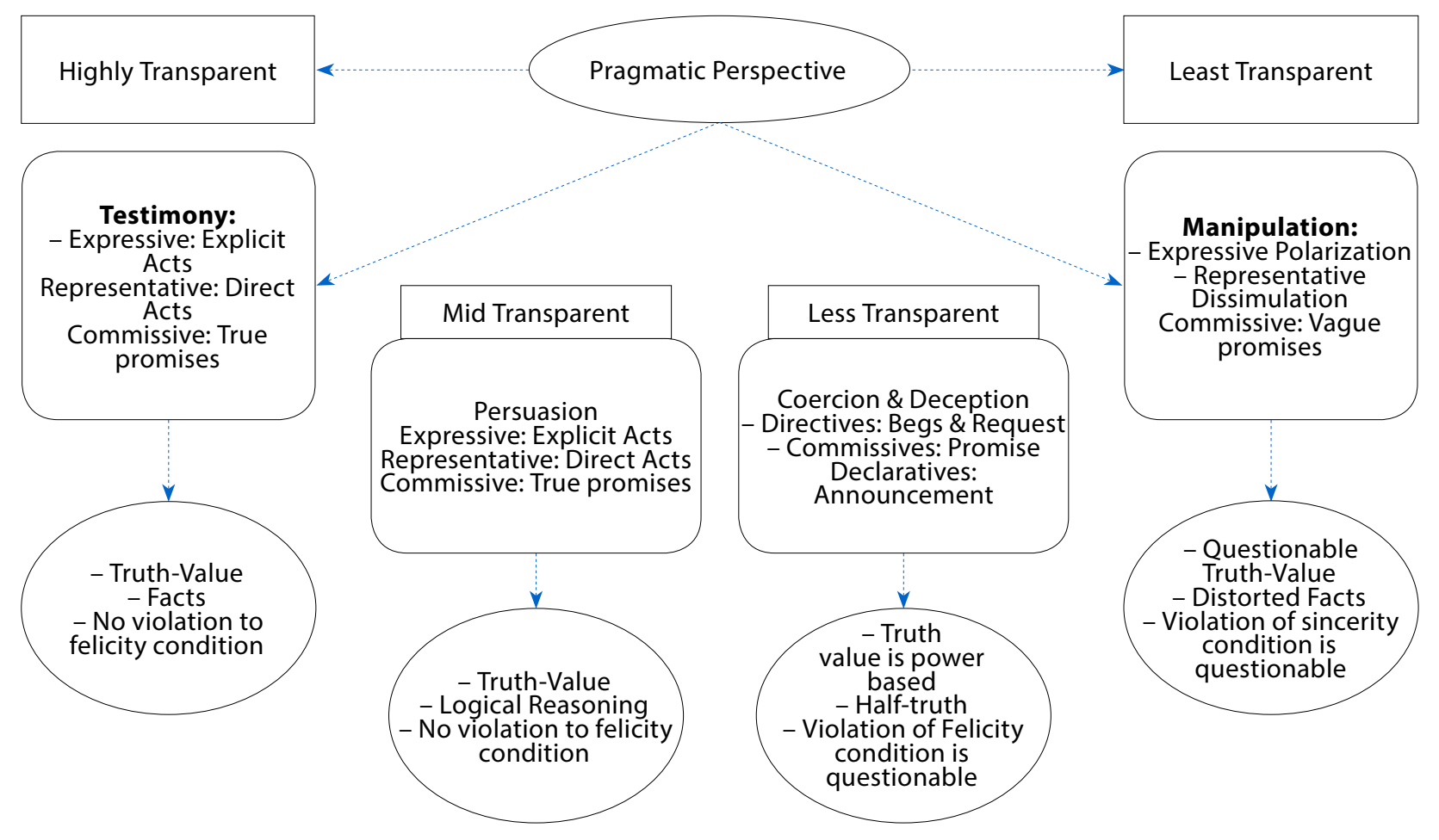

Figure 3. The transparency of the speaker from the pragmatic perspective

According to de Saussure, manipulation theory can come to practice when it is associated with strategies. The strategies are of two main types: the local strategies and the global strategies. The local strategies include the "rhetorical devices or questions", "misuse of concepts" and "the totalitarian manipulation". The rhetorical questions carry a strong presupposition, like the question "what else can we think?" and the question presupposes the answer "Nothing". The misuse of concepts includes the misuse of words such as "hero" or "heroism" for a person who is a dictator and describing the killing actions as heroic. The last one is the totalitarian manipulation which implies that the speaker wants a "God-like being" because he asks for "faith instead of rational agreement" (de Saussure 2005: 127-128).

The global strategies include the use of linguistic devices, such as repetition, numbers and acronyms or non-linguistic devices, such as group pressure and the creation of an image. The group pressure is reflected when the "individual tends to comply with the most salient opinion" and the images creation is the achievement of a "super-competent" image in the hearer's mind (de Saussure 2005: 130).

Other types of strategies are pragmatically based, such as the use of omission or vagueness and polarization. Omission or vagueness is defined as lacking of complements which can in turn be 
definite and indefinite. Definite omissions are found in the discourse whereas indefinite omissions have to be deduced from the context. Polarization, on the other hand, refers to the white and black colors or to the good and evil image that the participants may form based on the way a specific character or discourse is being identified. The transparency of polarization falls under three degrees, which are: obvious, less obvious and low obviousness. When the speaker's speech is obvious, the speaker is using specific words to show that something is part of the good or evil image. However, when the speaker is less obvious, the hearer has to make use of his knowledge of the context. The same is applicable if the degree of obviousness is low as it requires specific analyses of the lexeme or verbs used by the speaker (Danler 2005).

\section{Cycle two: The discourse itself and transparency}

Sorlin (2016) distinguishes three types of discourse: manipulation, deception and persuasion. The manipulation type exploits the resource of the normal language and the pragmatic acts. It can be measured on a continuum of power that imposes upon the addressee and it is less covert. The other type of discourse is deception. It is a type of discourse that is similar to manipulation with slight differences. It is a deliberate attempt to manipulate factual and emotional information. It has to do with the true/false dichotomy or half-truths. Manipulators rely heavily on the half-truth because lies are easily discovered and it demands immediate re-thinking on the part of the hearer. Lying is the most common way of deception. The persuasion, on the other hand, is different from manipulation because it is the act of convincing the addressee who has a degree of liberty.

Blass (2005) classifies discourse into three types: testimony, deception and argumentation. Testimony is a way of stating facts in a way that the speaker or hearer adheres to the mutual trust between them. On the other hand, deception is based on the falsehood of the proposition to convince people that it is true. Argumentation is only different from the other two terms as it may be true or false. Regardless of it being true or false, it should be supported by a proof or a reason. In argumentation the speaker should deal with reasons so that the hearer can accept his proposition even when the hearer has no confidence in the speaker's speech (Blass 2005:171-172).

This study argues that the effect of transparency or opaqueness is evident in these types of discourse. For instance, manipulative discourse is supposed to be far away from transparency and reflects a high degree of opaqueness because it may refer to a setting in which communication is needed to change or manipulate the behavior of others. Accordingly, a proposition is manipulative if it helps in changing "the vision of the world" in the hearer's mind and the speaker would be able to achieve his or her final goal and interest (Rigotti 2005:68). This view is also discussed by de Saussure (2005: 119) who suggests that: "A communication is manipulative when the speaker retains some relevant information, or provides the correct information but in order for the hearer to conclude that he should behave in a way which favours the speaker's interests, without being aware of it."

Manipulative discourse should always be covert. It is covert because the act of manipulating requires the people concerned to be expert at hiding their true intentions which are usually unidenti- 
fied (Morler 2006).The covert nature of manipulation makes it an act of intentionally changing other people's minds and it does not happen accidentally. If the speaker does it unintentionally, then he is making a mistake and it is not part of manipulation (Blass 2005). All the manipulation strategies should pass unnoticed and speaker's intention should remain concealed because it is not to the benefit of the hearer (Maillat \& Oswald 2009). Coercion represents a situation where a severe threat of harm is evident. Thus the hearer is unable to avoid it because it hurts the hearer physically without relying on the act of convincing. That is why it is different from persuasion (Kamil \& Fareed 2017).

This paper builds on the assumption that these types of texts can reflect different degrees of transparency. Testimony, for example, is highly transparent based on its truthfulness. It is shaped on a kind of trust between the speaker and the hearer without exerting any power or imposing any kind of lies and, most importantly, without changing the hearer's mind by manipulation. The high degree of transparency is supported by Blass's conception of testimony who states that testimony has a beneficial outcome with a desirable effect based on its truthfulness. Similarly, the argumentation has a high degree of transparency in comparison with deception because it involves a convincing process that is based on truth or falsehood of the statement.

According to Blass, a testimony may turn into argumentation when there is no trust between the speaker and the hearer. Argumentation or persuasion occurs in order to gain trust among participants. Therefore it is the study of giving reason to justify the people's statements or propositions. The speaker in this type of text can use both overt and covert strategies to get the required trust (Blass 2005). A different view is represented by de Saussure (2005:122) who states that the speaker may be involved in the process of persuasion when he is not "aware of reality", which means that "there is no possible discrepancy between his own interests and the freely evaluated interests of the audience".

Other text-types such as deception and coercion are supposed to have less degree of transparency. They have a low degree of transparency and a higher degree of opaqueness because they represent a deliberate attempt to manipulate factual or emotional information with the true-false dichotomy or half-truths. They are less transparent because they are misleading, indirect and make covert attempts to deceive others. The figure below presents the continuum of manipulative discourse types in terms of transparency.

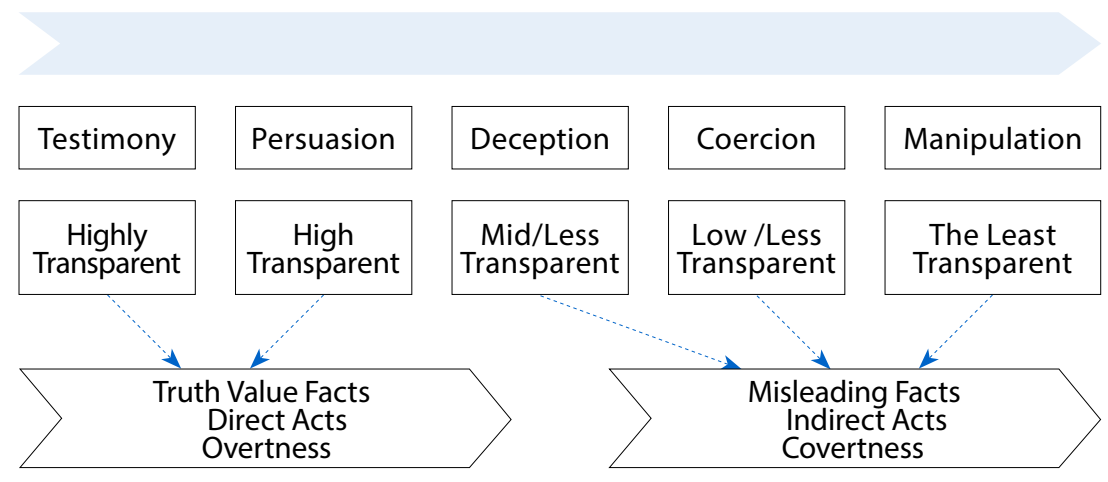

Figure 4. The suggested model of manipulative discourse and transparency 


\section{Stage three: The hearer}

The relation between the two participants in a manipulative discourse may take different forms based on: first the relation that is intended, and secondly on the goal which is planned for. These forms are proposed by Danler (2005) when he tries to explain the main strategies that a participant may use in manipulating others as follows:

\section{$\mathrm{Y}$ has relation to $\mathrm{X}$ by:}

a. $\mathrm{X}$ saying untrue things about $\mathrm{Y}$ to $\mathrm{Z}$.

b. X saying untrue things to $\mathrm{Y}$.

c. X making Y look ugly.

d. X making Y greater in degree.

e. X saying things to $\mathrm{Y}$ that cause pain to Y's feelings.

The speaker (X) is trying to build a relationship with the hearer in different ways, such as telling lies, distortion and hurting procedures. The speaker in (a) misleads the hearer by giving him wrong information about others. Similarly, the speaker in (b) is lying by giving untrue propositions. The situation is different in (c) and (d) because the speaker is changing the mind of the hearer by presenting ugly things about a proposition or by emphasizing untrue or half-true propositions.

In line with this, Maillat \& Oswald (2009) state that the manipulator can mislead the manipulatee by urging him to give up a legitimate belief, reinforcing a problematic belief or hiding the legitimate belief. All these are different from (a) and (b) which involve deception or lying.

The hearer in persuasion discourse, however, has the liberty to disagree with the arguments. However, it should be noted that the general hearer's rational capacity is underestimated in manipulative discourse (Sorlin 2016). A rather different view is given by Maillat Oswald (2009) who states that the hearer's attitude in manipulation is considered to be cooperative because he assumes that the speaker is direct and straight forward. It is a belief that the hearer possesses a mutual trust between himself and the speaker. That is why hearer may rely on his cognitive environment to form his own attitude.

De Saussure (2005) proposes two types of intentions that a hearer may use, namely, the informative or the communicate intentions within the relevance theory to assess the speaker's speech (mentioned previously in the suggested model). The classification of these two intentions within the framework of transparency is not in terms of the speaker's statements' truth value but on the hearer's choice. The use of communicative intention implies a high degree of transparency because the hearer believes that what is being said is true. However, the use of informative intention entails a low degree of transparency because the hearer has his own suspicion towards what is being said. The following figure shows the hearer's use of the two intentions. 


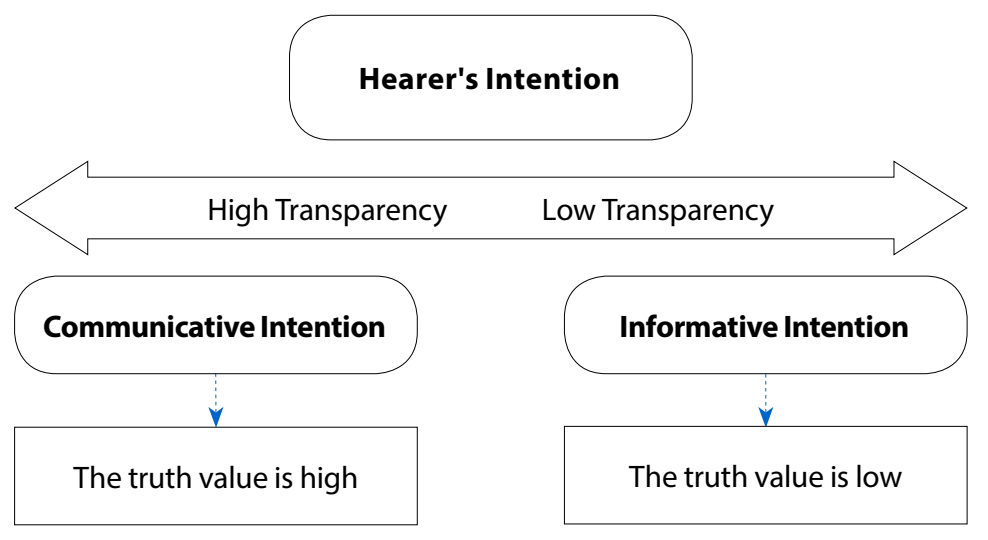

Figure 5. The hearer's intention and transparency

The hearer can create 'the relevant consequence' based on his current relation with the speaker. When he is not quite sure of the other's utterance or he has certain suspicions, he will use the informative intention. It leads to the hearer questioning the truth value of the speaker's proposition, which creates a low degree of transparency. However, the hearer may use the communicative intention when his relation with the speaker is based on mutual trust. This in turn paves the way to a higher degree of transparency.

This conclusion is supported by de Saussure (2005) who proposes that the hearer can rely on the cognitive environment whose truth is not matched with the falsehood or truthfulness of the proposition but it is matched with the hearer's intention.

\section{The application of the descriptive framework}

In this section two examples are given to represent the two extremes of manipulative texts which are the testimony and the manipulation. The first example is taken from Graham (2006) who presents a testimony text as a sample. The testimony sample is given by a schoolteacher to a group of students. In the previously introduced descriptive framework, it is proposed that the testimony text has a high degree of transparency because the speaker has no intention to manipulate the hearer but rather he is explaining a scientific text that has a high truth value. The schoolteacher gives his explanation as follows:

"In requiring that the source [the recipient's interlocutor] have knowledge if the recipient is to have knowledge based on interlocution, I oversimplify. Some chains with more than two links seem to violate this condition. But there must be knowledge in the chain if the recipient is to have knowledge based on interlocution."

The schoolteacher states facts as an agent whereas the students are the patients. Stating facts entails a highly transparent type of text where the agent has no intention to deceive his patients (students).The patients have to use the informative intention that reflects a high truth value because the text is a testimony that states facts. The text itself is highly transparent because a) the speaker uses direct and over strategies, b) he uses an expressive, representative and commissive and in a direct way, and c) the use of the linguistic device of repetition to make the text understandable. 
The second example is taken from an analysis of a political text. It is given by Emeka and Ngozi (2016). They describe a speech given by Obasanjo when he becomes the president of Nigeria. In his speech he makes a connection between himself and God:

"FELLOW Nigerians, we give praise and honour to God Almighty for this day specially appointed by God Himself. Everything created by God has its destiny and it is the destiny of all of us to see this day."

According to Emeka and Ngozi (2016), Obasanjo uses the manipulative strategy to paint the picture of a messenger who was sent to save Nigeria from corruption. He makes use of the fact that people of Nigeria are religious to manipulate their minds by implicitly stating that he has been chosen by God to save them.

Based on the earlier description, it seems that these types of texts have a low degree of transparency because the speaker acts as an agent that has a superior status. In fact he is chosen by God, whereas the hearers are the patients who are passive recipients of the president's speech. His religious hearers will be affected by this speech and choose to employ the communicative intention that has a high truth value and the speech is evaluated by the hearers or the patients as highly transparent. However, other patients who have sufficient political knowledge may use the informative intention when they have a suspicious attitude towards the speech.

The manipulative speech accordingly has a low degree of transparency. This result is achieved because the hearers are being manipulated as they cannot realize the speaker's covered intentions behind what is being said. The given speech is covert and indirect. Thus, the types of the texts that are analyzed may have various degree of transparency. The degree of transparency is controlled by the speaker's intentions. Stating facts is highly transparent, which stands in contrast with manipulative texts, which are the least transparent.

\section{Conclusion}

Based on the proposed three-cycle theoretical framework it seems that manipulation discourse may fall under different categorizations that show various degrees of transparency. Thus manipulation does not necessarily mean 'to change somebody's mind by telling lies'. Rather it has many other implications, such as stating facts in testimony or arguing with a proof in persuasion. Each type of manipulative discourse has its implications. The deepest effect on the type of manipulation discourse is carried out by the participants. The roles of the speaker and the hearer vary according to their belief. The speaker is either stating the truth or he is unaware of the falsehood of his statement. In both cases, the testimony type of manipulative discourse is formed. However, he can deliberately intend to manipulate the hearer. This forms the other extreme, which is the manipulative text. The manipulator's strategies are highly dependent on the type of manipulation discourse they are involved in. This paves the way to other types of manipulative discourse, such as coercion and deception. The hearer, in turn, is free to accept or reject that based on his or her communicative or informative intention. 
Finally, manipulative discourse has various degrees of transparency. It is proposed that the factors of overtness, direct speech and truth value have an effect in creating a high degree of transparency and these factors are evident in the testimony types of manipulative discourse. On the other hand, the use of covertness, indirect speech and falsehood can lead to a lower degree of transparency and a higher degree of opaqueness.

\section{References}

Blass, Regina. 2005. Manipulation in the speeches and writings of Hitler and the NSDAP from a relevance theoretic point of view. In: L. de Saussure and P. Schulz (eds.), Manipulation and Ideologies in the Twentieth Century: Discourse, Language, Mind, 169-190. Amsterdam/Philadelphia: John Benjamins Publishing.

Danler, Paul.2005. Morpho-syntactic and textual realizations as deliberate pragmatic argumentative linguistic tools. In: L. de Saussure and P. Schulz (eds.), Manipulation and Ideologies in the Twentieth Century: Discourse, Language, Mind, 45-60. Amsterdam/Philadelphia: John Benjamins Publishing.

Emeka-Nwobia \& Ngozi U.2016. Political manipulation in Nigerian presidential discourses. British Journal of English Linguistics 4(4). 12-23.

Fairclough, Norman. 2003. Analysing Discourse: Textual Analysis for Social Research. London: Routledge.

Graham, Peter J. 2006. Can testimony generate knowledge? Philosophica 78. 105-127.

Ilie, Cornelia. 2005. An integrated approach to the analysis of participant roles in totalitarian discourse. In: L. de Saussure and P. Schulz (eds.), Manipulation and Ideologies in the Twentieth Century: Discourse, Language, Mind, 191-211. Amsterdam/Philadelphia: John Benjamins Publishing.

Kamil, Salwa Ibrahim, and Fareed Hameed Al-Hindawi. 2017. The Pragmatics of Manipulation in British and American Political Debates. Hamburg: Anchor Academic Publishing.

Maillat, Didier, and Steve Oswald. 2009. Defining manipulative discourse: The pragmatics of cognitive illusions. International Review of Pragmatics 1(2). 348-370.

Morler, Edward E. 2006. The Leadership Integrity Challenge: Assessing and Facilitating Emotional Maturity. Tel Aviv-Yafo: Sanai Publishing.

Portis, Edward Bryan, Adolf G. Gundersen, and Ruth Lessl Shively (eds.) 2000. Political Theory and Partisan Politics: Matter the Body Itself. Albany: SUNY Press.

Rigotti, Eddo. 2005. Towards a typology of manipulative processes. In: L. de Saussure and P. Schulz (eds.), Manipulation and Ideologies in the Twentieth Century: Discourse, Language, Mind, 61-83. Amsterdam/Philadelphia: John Benjamins Publishing.

de Saussure, Louis. 2005. Manipulation and cognitive pragmatics: Preliminary hypotheses. In: L. de Saussure and Peter J. Schulz (eds.), Manipulation and Ideologies in the Twentieth Century: Discourse, Language, Mind, 113-146. Amsterdam/Philadelphia: John Benjamins Publishing. 
Sorlin, Sandrine. 2016. Language and Manipulation in House of Cards: A Pragma-stylistic Perspective. London: Palgrave Macmillan.

Van Dijk, Teun A.2006. Discourse and manipulation. Discourse \& Society, 17(3). 359-383.

Vadia, Kata. 2016. Critical discourse analysis in progress: the power, ideology and manipulation identification (PIMI) model. Alkalmazott Nyelvtudomány 16, doi: http://dx.doi.org/10.18460/ ANY.2016.1.004 